\title{
Airway Obstruction Correlates with Collagenase-2 (MMP-8) Expression and Activation in Bronchial Asthma
}

\author{
Kaiu Prikk, Päivi Maisi, Emma Pirilä, Mari-Ann Reintam, Tuula Salo, Timo Sorsa, \\ and Ruth Sepper
}

Institute of Experimental and Clinical Medicine (KP, M-AR, RS), The North-Estonian Regional Hospital (RS), Tallinn, Estonia; Department of Clinical Veterinary Sciences (PM, EP), Faculty of Veterinary Medicine, University of Helsinki, Department of Oral and Maxillofacial Diseases (KP, EP, T. Sorsa), Institute of Dentistry, Helsinki University Central Hospital (HUCH), University of Helsinki, Orton Research Institute and the Orthopaedic Hospital of Invalid Foundation, Helsinki (T. Sorsa) and Departments of Oral Diagnostics and Pathology (T. Salo), University of Oulu, Oulu, Finland

SUMMARY: Matrix metalloproteinases (MMPs) contribute to extracellular matrix and basement membrane degradation in asthma. The present study analyzed molecular forms and degree of activation and expression of MMP-8 in bronchoalveolar lavage fluid (BALF), BALF cells, and bronchial tissue specimens from 14 steroid-naive asthma patients, 13 uncontrolled severe asthma patients, 13 controlled asthma patients, and 14 healthy subjects by Western immunoblotting, immunohistochemistry, and in situ hybridization. Immunohistochemistry and in situ hybridization revealed a prominent MMP-8 immunoreactivity in submucosal inflammatory, glandular, and shed, but not in intact bronchial epithelial cells of asthma patients. In BALF cytospins, both MMP-8 protein and mRNA expression were observed in epithelial cells, macrophages, and polymorphonuclear leukocytes (PMNs). MMP-8 was present in BALFs asthma patients in complex, pro- and active PMN-type, and pro- and active non-PMN-type forms. BALF MMP-8 was significantly converted to active form only in BALFs from steroid-naive and uncontrolled severe asthma patients, but not in BALFs from well-controlled asthma patients or healthy controls. A significant inverse correlation between BALF MMP-8 levels and FEV $1(r=-0.283, p=0.04)$, and BALF activated MMP-8 forms and FEV 1 ( $r=$ $-0.427, p=0.001$ ) was detected. Overall, these data suggest that MMP-8 and its activation has an important role in the airway destruction, healing, remodeling, and treatment response in asthma. (Lab Invest 2002, 82:1535-1545).

$C$ hronic mucosal inflammation and airway remodeling are the key events in the development of bronchial asthma (BA) even in mild and early forms of the disease (Bousquet et al, 2000; Laitinen et al, 1985). In more advanced stage, thickening of the subepithelial basement membrane (BM), deposition of fibrillar collagen, and disruption of elastic fibers have been detected (Bousquet et al, 1996; Redington and Howarth, 1997). Degradative processes of extracellular matrix (ECM) and BM components in airways are

DOI: 10.1097/01.LAB.0000035023.53893.B6

Received July 9, 2002.

Ruth Sepper, Päivi Maisi, and Timo Sorsa supervised the work equally. This work was supported by the Finnish Technology Development Center (TEKES), the Finnish Academy, the Helsinki University Research Funds, the Wilhelm and Else Stockman Foundation, the Centre for International Mobility (CIMO), the Biomedicum Rekärela Foundation, the Estonian Scientific Foundation, the Estonian Education Ministry, the Estonian Relief Committee, and Estonian Students Fund in the USA.

Address reprint requests to: Dr. Kaiu Prikk, clo Dr Timo Sorsa, Oral Pathology Unit at Biomedicum Helsinki, 2nd floor, University of Helsinki, PL 63 (Haartmaninkatu 8), 00014 Helsinki, Finland. E-mail: kaiu.prikk@helsinki.fi tightly controlled by a delicate balance between induction, expression, activation, and inhibition of matrix metalloproteinases (MMPs). The MMP family plays a crucial role in various tissue destructive conditions, such as malignancies, arthritides, and skin and periodontal diseases, as well as in physiologic tissue remodeling and repair (Birkedal-Hansen et al, 1993; Shapiro, 1998). Up-regulated MMPs have been found in BA; gelatinase B (MMP-9) and its tissue inhibitor of MMPs (TIMP-1) have been shown to be expressed in an unbalanced ratio in bronchoalveolar lavage fluid (BALF) and induced sputum from asthma patients (Mautino et al, 1997, 1999; Vignola et al, 1998; Warner et al, 1997). Abundant expression of MMP-9 and -3 has been localized to asthmatic bronchial tissue macrophages, lymphocytes, eosinophils, and neutrophils, indicating that various genetically distinct MMPs are involved in destructive processes also in asthmatic airways (Dahlen et al, 1999; Kumagai et al, 1999; Ohno et al, 1997).

Collagenase-1 (MMP-1), -2 (MMP-8), and -3 (MMP13) form an interstitial collagenase subfamily of MMPs (Birkedal-Hansen et al, 1993). Regarding fibrillar or interstitial collagens, MMP-8 hydrolyzes most efficiently type 
I collagen (Hasty et al, 1987), which is the major interstitial collagen type in human lung ECM (Crystal and Weibel, 1991), and further degrades types VII and X collagens (Shmid et al, 1986). MMP-8 inactivates proteolytically serine proteinase inhibitors $\alpha_{1}$-antitrypsin and $\alpha_{1}$-antichymotrypsin, and also a general proteinase inhibitor $\alpha_{2}$-macroglobulin (Michaelis et al, 1990; SottrupJensen, 1989; Weiss, 1989).

MMP-8 has previously been considered to be derived only from degranulating polymorphonuclear leukocytes (PMNs) at the site of inflammation (Weiss, 1989), but recent studies have evidenced that certain non-PMN lineage cells, such as human bronchial epithelial cells (Prikk et al, 2001), sulcular epithelial cells (Tervahartiala et al, 2000), chondrocytes (Chubinskaja et al, 1996; Cole et al, 1996), synovial fibroblast and endothelial cell (Hanemaaijer et al, 1997), odontoblasts (Palosaari et al, 2000), and plasma cells (Wahlgren et al, 2001), can express MMP-8 protein and mRNA. Moreover, malignant epithelial cells (Bachmeier et al, 2000) and rat wound keratinocytes express MMP-8 (Pirilä et al, 2001). Sixty-kilodalton MMP-8 has been cloned and characterized from mouse embryogenic and peritoneal inflammatory neutrophil-enriched cell populations (Balbin et al, 1998).

The principal aim of the present study was to evaluate the involvement of collagenase-2 (MMP-8) in the progression of asthmatic tissue remodeling. The study provides evidence for the up-regulation and activation of various MMP- 8 species in BALF, as well as expression of MMP-8 in bronchial tissue and BALF cells. In addition, we show a clear inverse correlation between BALF MMP-8 levels and FEV 1 decline, which together with inhaled steroids (ICS) treatment effect in asthma patients.

\section{Results}

\section{Western Immunoblot Results of BALF MMP-8 from Asthma Patients and Healthy Controls}

Two groups of MMP-8 molecular species were detected at approximately 70 to $80 \mathrm{kd}$, evidently representing latent and activated forms of highly glycosylated PMN-type MMP-8, and two species at approximately 50 to $60 \mathrm{kd}$, representing latent and activated forms of less-glycosylated non-PMN-type MMP-8 (Hanemaaijer et al, 1997; Prikk et al, 2001). Additionally, high molecular weight forms ( $>80 \mathrm{kd}$ ) evidently representing complexed inhibitor-bound or dimeric forms of MMP-8, were observed (Fig. 1).

The profiles of the detected immunoreactive MMP-8 species are shown in Figure 2. BALFs from controlled $\mathrm{BA}$ and healthy controls demonstrated only weak and hardly detectable immunoreactivities of latent MMP-8 forms. Total MMP-8 immunoreactivities in BALF from steroid-naive $B A$ and uncontrolled $B A$ were significantly elevated relative to BALF from healthy controls ( $p<0.01, p<0.001$, respectively). Furthermore, total MMP-8 immunoreactivities in BALF from uncontrolled BA significantly differed from that of BALF from con-

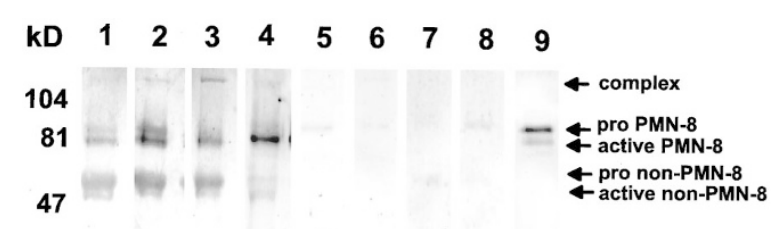

\section{Figure 1.}

Western immunoblot for matrix metalloproteinase (MMP)-8 in bronchoalveolar lavage fluid (BALF) of bronchial asthma patients and healthy controls. BALF samples from steroid-naive bronchial asthma (BA) (Lanes 1 and 2), uncontrolled BA (Lanes 3 and 4), controlled BA (Lanes 5 and 6 ), and healthy controls (Lanes 7 and 8) show complex forms of MMP-8, pro- and active forms of the polymorphonuclear leukocytes (PMN)-type MMP-8 and pro- and active forms of the non-PMN type MMP-8. Lane 9 shows purified human PMN-type MMP-8. Molecular weight standards are shown on the left.

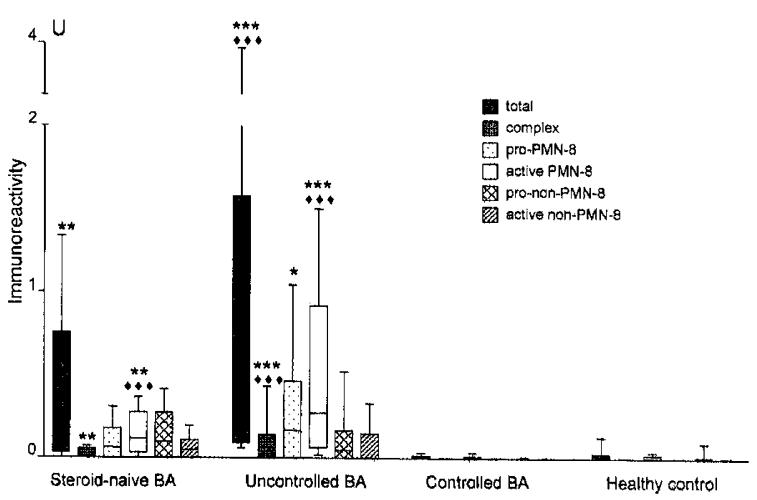

Figure 2.

MMP-8 immunoreactivity in BALF from asthma patients and healthy controls. Quantitation of MMP-8 protein in BALF, analyzed by Western immunoblotting, was performed with an image analyzer and the results are presented as densitometric scanning units $(U)$. The median and the ranges (boxes) are shown. * $p<0.05$ compared with healthy control; ** $p<0.01$ compared with healthy control; ${ }^{* * *} p<0.001$ compared with healthy control; $\diamond \diamond \diamond p<$ 0.001 compared with controlled BA.

trolled BA $(p<0.001)$. The same profile concerning complex forms of MMP-8 in BALF from steroid-naive $\mathrm{BA}$ and uncontrolled BA significantly differed from that in healthy controls ( $p<0.01, p<0.001$, respectively) and the MMP-8 complex form in uncontrolled BA differed from that of BALF from controlled BA $(p<$ 0.001). Elevated levels of activated PMN-type MMP-8 were detected in BALF from uncontrolled BA and steroid-naive BA when compared with BALF from controlled BA ( $p<0.001, p<0.001$, respectively) and healthy controls ( $p<0.001, p<0.01$, respectively). Latent PMN-type MMP-8 species were significantly elevated only in BALFs from uncontrolled BA as compared with healthy controls $(p<0.05)$. The increase in latent and activated non-PMN-type MMP-8 was not significant in BALF from steroid-naive BA and uncontrolled BA.

\section{MMP-8 Immunolocalization in Bronchial Tissue and BALF Cells from Different Asthma Patients}

Immunohistochemistry and immunocytochemistry were used to localize MMP-8 protein in bronchial biopsies and cytospin BALF cells from BA patients 
and controls. The pathomorphologic pattern was typical for BA, including thickened BM and submucosal infiltration by inflammatory cells. Epithelial shedding in bronchial biopsies from BA patients differed from totally intact to an extensively shed entire epithelium. Table 3 summarizes the grade of epithelial shedding in individual BA patients. In those specimens where bronchial epithelium was intact and/or only mildly shed, the MMP-8 expression was prominent in submucosal and epithelial area inflammatory cells; however, epithelial cells did not express MMP-8 (Fig. 3A). In contrast, the bronchial specimens with moderate to extensive epithelial shedding presented a strong MMP-8 immunopositivity focally and especially in bronchial epithelial cells in addition to the infiltrating inflammatory cells of bronchial submucosal area (Fig. 3B). It also appears that MMP-8 protein was partially secreted into the extracellular milieu as shown by immunoreactive granules in the intercellular area (Fig. 3 , B and C). Furthermore, MMP-8 protein was detected in serous cells of submucosal glands and in a secretion within the acini (Fig. 3C). A semiquantitative analysis of MMP-8 immunoreactivity in bronchial biopsy specimens is presented in Table 3.

BALF cells from steroid-naive and uncontrolled BA patients showed a strong immunoreactivity for MMP-8 protein in unciliated bronchial epithelial cells (Fig. 3G), as well as in PMNs (Fig. 3F). A weaker but clear signal of MMP-8 immunoreactivity was also detected in macrophages of patients with steroid-naive and uncontrolled BA (Fig. 3G). BALF cells from controlled asthma patients showed a weak MMP-8 immunoreactivity in macrophages. A minimal hardly detectable MMP-8 signal in monocytes/macrophages from healthy controls in BALF cells (Fig. 4A) and in bronchial specimens (Fig. 4C) was detected.

\section{Expression of MMP-8 mRNA in BALF Cells and Bronchial Biopsies from Asthma Patients}

In agreement with immunocytochemical stainings, a strong signal for MMP-8 mRNA was detected in BALF PMNs, unciliated epithelial cells, and macrophages (Fig. 3, $\mathrm{H}$ and I) by in situ hybridization. MMP-8 mRNA was observed in ciliated and unciliated epithelial cells in addition to inflammatory cells in bronchial tissue biopsies (Fig. 3, L and M). Control slides with MMP-8 sense probe gave no hybridization signal (Fig. 3, K and $\mathrm{N})$.

\section{Relationship Between the Total and Activated MMP-8 Immunoreactivities and FEV ${ }_{1}$ Values of BALF from Asthma Patients and Healthy Controls}

Spearman rank correlation analysis was used to relate the $\mathrm{FEV}_{1}$ values and total MMP-8 immunoreactivity and total activated MMP-8 immunoreactivity in BALF. A significant inverse correlation was observed

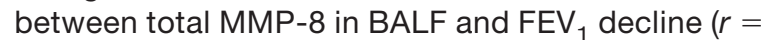
$-0.283, p=0.04$, Fig. 5A) and activated MMP-8 in BALF and FEV 1 decline $(r=-0.427, p=0.001$, Fig. 5B). Importantly, steroid-naive BA with slight airway obstruction and uncontrolled BA with severe airway obstruction showed mainly elevated MMP-8 immunoreactivity, whereas in the controlled BA patients group with slight airway obstruction, the MMP-8 levels remained low.

\section{Content of Total Protein, Eosinophilic Cationic Protein, and Cell Profile in BALF from Asthma Patients and Healthy Controls}

Concentration of total protein, eosinophilic cationic protein (ECP), and cell profile in BALF are summarized in Table 2. No significant differences in total protein and ECP levels were found between asthma patients and healthy controls. The total number of cells recovered in the BALF was elevated only in steroid-naive BA compared with healthy controls $(p=0.03)$. No other significant differences were found in cell counts in the BA groups compared with healthy controls.

\section{Discussion}

$\mathrm{BA}$ is a disease with variable airway obstruction; the severity and exacerbation of the obstruction are assessed by a decline of $\mathrm{FEV}_{1}$ value. $\mathrm{FEV}_{1}$ is used to clinically evaluate and predict lung function of asthma patients (Peat et al, 1987). This study demonstrated a significant inverse correlation between levels and activation of BALF MMP-8 and $\mathrm{FEV}_{1}$ values in asthma patients. The secreted MMP-8 in BALFs was, to a significant extent, converted into active form in steroid-naive and uncontrolled severe asthma patients, but not in BALF from controlled and clinically stable asthma patients or from healthy controls. Focal and strong MMP-8 immunoreactivity was detectable especially in bronchial epithelial cells of injured and shed asthmatic airway. In addition, submucosal inflammatory and serous gland cells revealed MMP-8 immunopositivity. Immunostaining and in situ hybridization of BALF cell cytospins confirmed that bronchial epithelial cells, macrophages, and PMNs express both MMP-8 protein and mRNA in asthma.

Previously, only mature circulating PMNs have been thought to be the primary cellular source and storage of MMP-8 at the site of inflammation (Weiss, 1989). Release and activation of MMP-8 without de novo expression of PMNs have thus been considered to be mainly regulated by factors affecting PMN triggering and degranulation (Weiss, 1989). Certain mesenchymal cell lines and plasma cells have recently been demonstrated to express MMP-8 protein and mRNA (Bachmeier et al, 2000; Cole et al, 1996; Hanemaaijer et al, 1997; Palosaari et al, 2000; Pirilä et al, 2001; Tervahartiala et al, 2000; Wahlgren et al, 2001). Furthermore, bronchial epithelial cells express MMP-8 (Prikk et al, 2001) and also other MMPs such as MMP-2, -7, and -9 (Dunsmore et al, 1998; Yao et al, 1996), which can mediate tissue destruction in cascades by activating each other. We found clear MMP-8 mRNA expression in PMNs in BALF cells from uncontrolled severe asthma patients, showing that PMNs at the site of inflammation are capable of de novo expressing PMN-type MMP-8 in asthma. This 

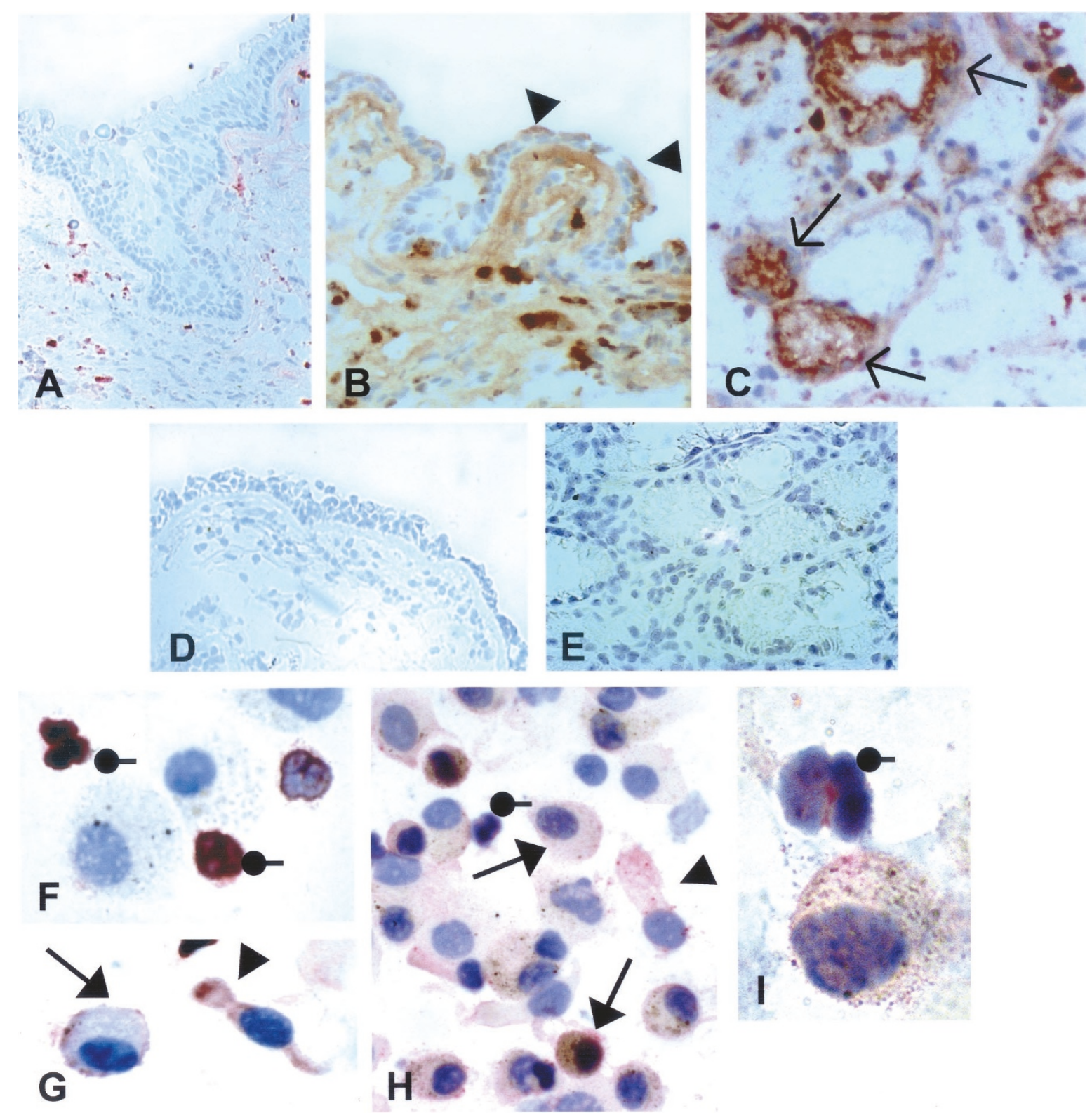

Figure 3.

Localization of MMP-8 protein in bronchial tissue biopsies and MMP-8 protein and mRNA in BALF cells from asthma patients. Immunoreactive MMP-8 is localized to submucosal inflammatory cells (A). Bronchial epithelial cells in the shed area intensively and focally express MMP-8 (B, arrowheads), whereas no apparent MMP-8 expression is observed in bronchial epithelial cells of intact epithelium (A). MMP-8 protein expressed by serous cells of submucosal serous glands (C, arrows). Bronchial sections incubated with nonimmunized rabbit IgG as controls ( $D$ and $E$ ). BALF cells from uncontrolled severe BA patients revealed strong MMP-8 protein expression in PMNs ( $F$, circular arrows) and epithelial cells (G, arrowhead) and weaker expression in macrophages (G, arrows). MMP-8 mRNA (H and I) detected in bronchial epithelial cells (arrowheads), macrophages (arrows), and PMNs (circular arrow). No signals were detected in slides incubated with nonimmunized rabbit IgG (J) or after hybridization with the MMP-8 sense probe (K). MMP-8 mRNA in ciliated epithelial cells (L, arrowhead) and unciliated epithelial cells (M, arrowhead) in addition to inflammatory cells $(\mathrm{M})$. No signals were detectable in parallel sections hybridized with the MMP-8 sense probe (N). Original magnifications, $A$, $\times 25$; B, C, D, E, M, and N, ×40; F, G, H, J, K, and L $\times 100 ;$ I, $\times 120$.

confirms and further extends the opinion of the previous studies that MMP-8 mRNA expression occurs in circulating PMNs (Cole and Kuettner, 1995; Hanemaaijer et al, 1997). MMP-8 protein was further detected in glandular cells and in glandular secretions. Associations of MMP-8 with glandular secretion, hyperplasia, and hypersecretion remains to be further studied.
Our study revealed up-regulated levels of total MMP-8 immunoreactivity as well as PMN and nonPMN MMP-8 species in BALF from steroid-naive BA and uncontrolled severe BA patients. We also found elevated levels of high molecular weight ( $>80 \mathrm{kd}$ ) complexes, representing MMP-8 species bound by endogenous inhibitors (TIMPs, $\alpha_{2}$-macroglobulins) and/or formed by dimerization of MMP-8. These data 


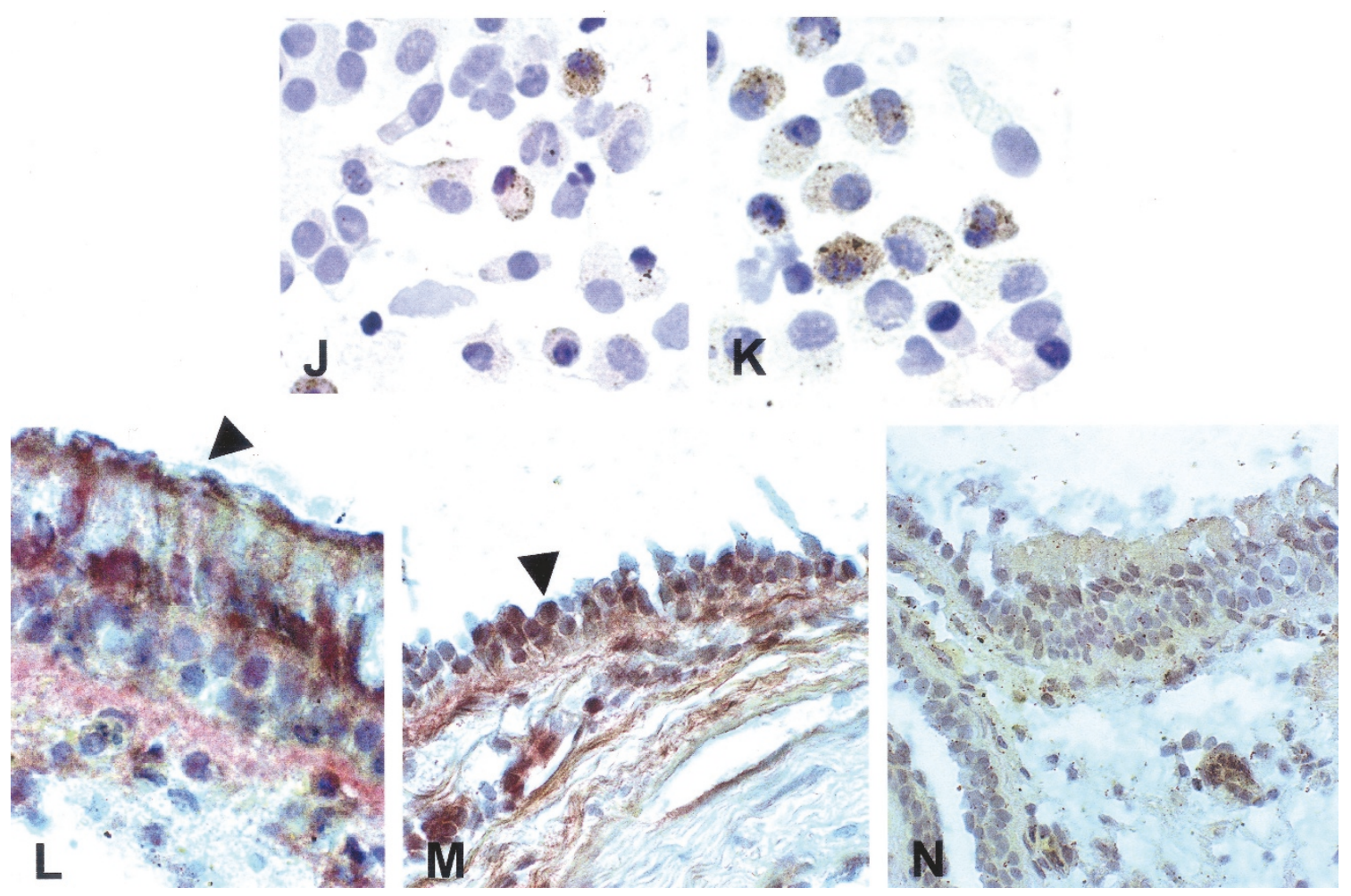

Figure 3.

(continued).

indicate that at early onset of asthmatic airway inflammation, represented by newly detected steroid-naive BA patients, a marked increase in MMP-8 expression occurs. MMP-8 in asthmatic airway is originating from epithelial cells, glandular cells, macrophages, and less from PMNs. This study confirms and further extends our recent results of BALF MMP-8 from bronchiectatic patients; pathologically elevated levels of both PMN and non-PMN MMP-8 species are significantly converted to active forms in the lung characterized by extensive tissue injury (Prikk et al, 2001).

In asthma, the airway epithelium is the major site of asthma-like perpetuated inflammation and remodeling
(Laitinen et al, 1985). Epithelium by itself actively contributes to the induction and development of the asthmatic process (Goldie et al, 1992). Bronchial epithelial cells are the first physiologic barrier cells against outside air contaminants and react during the inflammatory process by releasing various proinflammatory mediators against invading microbes, allergens, and airway irritants to stabilize epithelial functions (Polito and Proud, 1998). In the airways of patients having a genetic orientation to asthma, the delicate balance between injury and repair have evidently been lost, and continuing asthmatic inflammation leads usually to injury overcoming the repair. In

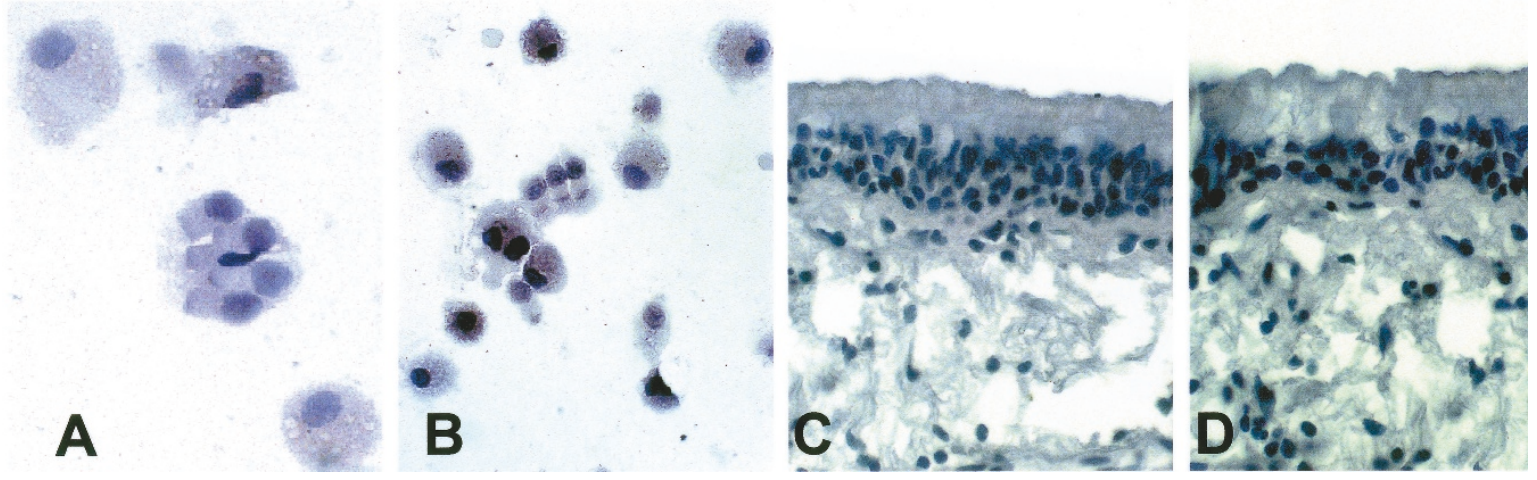

Figure 4.

Localization of MMP-8 protein in BALF cells and bronchial tissues from healthy controls. A hardly detectable MMP-8 signal in BALF cell macrophages (A) and monocytes/macrophages in bronchial tissues (C) from healthy controls. BALF cells and bronchial sections incubated with nonimmunized rabbit IgG as controls (B and $D$, respectively). Original magnifications, $A, C, D, \times 40 ; B, \times 25$. 
this study, the focal and strong MMP-8 expression was especially shown in the epithelial cells of shedding and damaged epithelium. No MMP-8 protein could be detected in the intact/repaired asthmatic epithelium, suggesting a rather different character of distinct stages of destructive processes occurring locally in asthmatic airways with or without advanced tissue injury. MMP-8 is a powerful enzyme degrading collagen types I, II, III, VII, VIII, and X, and also gelatin (Birkedal-Hansen et al, 1993; Hasty et al, 1987; Shapiro, 1998; Shmid et al, 1986). High MMP-8 levels in the inflamed airway epithelium indicate elevated risk for focal subepithelial collagenolysis. In asthma, continuous inflammation, injury, and repair lead to deposition of collagen types I, III, and V and fibronectin into subepithelial BM instead of functionally proper collagen type IV and laminin (Roche et al, 1989). High expression of MMP-8 in the shedding epithelium seems to refer more to an onset of an irreversible injury of specifically functioning bronchial epithelium and submucosal BM rather than inflammation itself. In this regard we have recently shown a prominent expression of MMP-8 protein and MRNA in the ciliated bronchial epithelial cells and macrophages in the airways of bronchiectasis patients, and hardly any

A

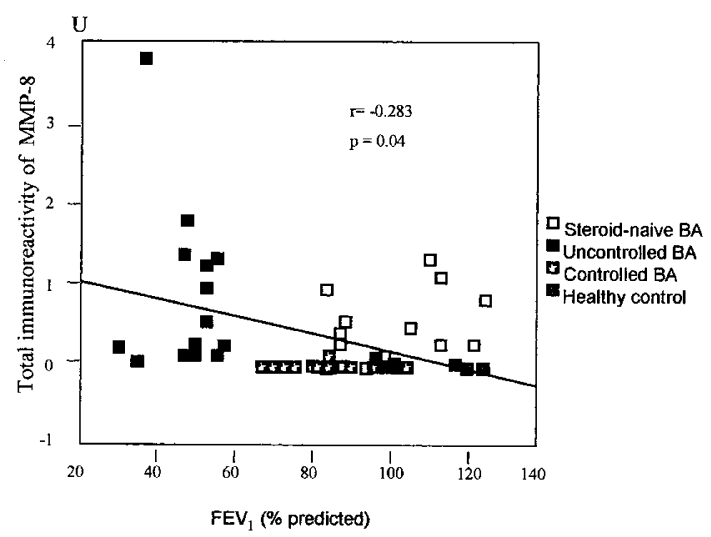

B

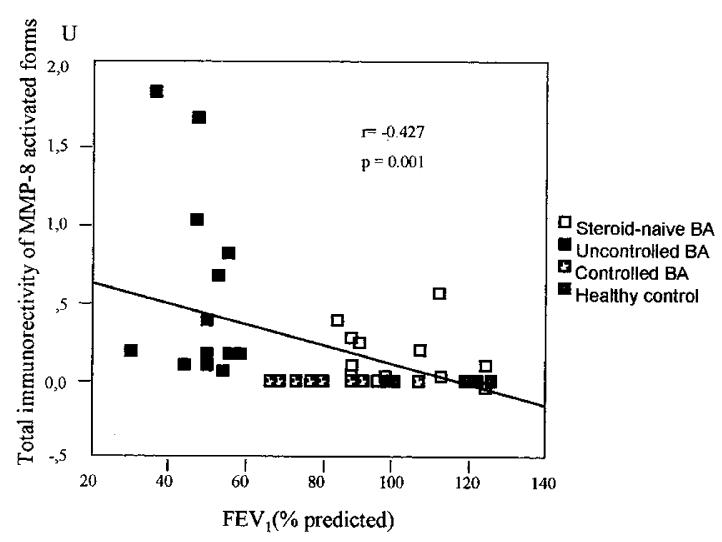

Figure 5.

Correlation between total MMP-8 immunoreactivities or activated MMP-8 species in BALF and FEV 1 values. A significant negative correlation is

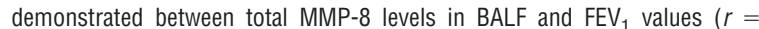
$-0.279, p=0.043)(A)$ and between immunoreactivity of activated MMP-8 species in BALF and FEV 1 values $(r=-0.427, p=0.01)(\mathrm{B})$.
MMP-8 signal was detectable in control specimens (Prikk et al, 2001). Bronchiectasis has always been characterized by irreversible tissue injury where pathologically elevated BALF proteolytic activity has been shown to correlate with disease severity (Sepper et al, 1995).

Lung function measurements are traditionally used in clinical characterization of the asthmatic process. $\mathrm{FEV}_{1}$ measurements have been implicated to assess and predict severity, activity, and treatment failure of asthma (American Thoracic Society, 1987; Peat et al, 1987). A strong inverse correlation between $\mathrm{FEV}_{1}$ and BALF MMP-8 levels of individual asthma patients shows a principal association between elevated MMP-8 activity and a risk for deterioration of the lung function. This is in accordance with and further extends the recent findings by Vignola et al (1998) demonstrating that sputum MMP-9/TIMP-1 ratio correlated with airway obstruction in asthma. We showed various MMP-8 levels in different stages of asthma; BALF from controlled asthma patients in clinical remission had MMP-8 levels comparable to healthy controls, whereas asthma patients with uncontrolled disease and clear evidence of treatment failure or newly detected steroid-naive asthma patients shared significantly elevated MMP-8 levels in their BALF. ICSs, principal components of asthma treatment (Barnes, 1993) have been shown to down-regulate BA inflammation and injury (Djucanovic et al, 1992; Jeffery et al, 1992) by reducing inflammatory cell infiltration into epithelial and subepithelial area, thus protecting ECM and BM from degradation in asthma. ICSs downregulate MMP activity in murine model of airway inflammation (Corbel et al, 1999; Shapiro et al, 1991), and protect the integrity of lamina reticularis by modulating MMP-9/TIMP-1 balance in asthmatic airways (Hoshino et al, 1999). Our current findings that treatment with high ICS doses of uncontrolled severe BA patients does not reduce the MMP-8 levels and/or activity and asthma symptoms refer to the possibility that a failure in ICS treatment may be associated with poor MMP-8 down-regulation as well. Probably, steroid resistance has a link to the inability of the downregulating MMP-8 protein and mRNA expression in asthmatic airways.

In summary, successful down-regulation of asthmatic inflammation occurs in parallel with reduction of MMP-8 degradative levels and activity in asthmatic airways. This evidence significantly associates MMP-8 activity with $\mathrm{FEV}_{1}$ measurements and further, with the MMP-8 value as an optional diagnostic tool (Sorsa et al, 1999) to evaluate integrity and functionality of asthmatic airways.

\section{Materials and Methods}

\section{Study Groups}

Forty patients with well-documented history and clinical findings of BA, based on American Thoracic Society (1987) recommendations, referred to the Department of Lung Diseases of Tartu University (Esto- 
nia) were included in this study. All patients had reversible airway obstruction as characterized by an increase of $15 \%$ in their $\mathrm{FEV}_{1}$ value and of $200 \mathrm{ml}$ absolute $\mathrm{FEV}_{1}$ value after inhalation of $200 \mu \mathrm{g}$ of salbutamol (Ventolin, Glaxo-Welcome, London, United Kingdom). The clinical severity of chronic asthma was based on the step system of the Global Initiative for Asthma (GINA), which grades asthma from intermittent to chronic mild, moderate, and severe persistent (Guidelines for diagnosis and management of asthma, 1997). All subjects were lifelong nonsmokers and none had had any viral infection during the 6 weeks before the study. History of allergy was proved by skin prick tests with a panel of commonly used allergens (ALK-Abello; Allergologisk Laboratorium $\mathrm{A} / \mathrm{S}$, Horsholm, Denmark).

BALF was obtained from three different groups of BA patients (Table 1): Group 1, steroid-naive ( $n=14$, median age 32.5 years, $\mathrm{FEV}_{1} \geq 70 \%$ ) patients with mild persistent but newly detected and untreated asthma. Group 2, patients with uncontrolled, severe persistent BA $\left(n=13\right.$, median age 48 years, $\mathrm{FEV}_{1} \leq$ $60 \%$ ), regularly treated with a daily dose of 1500 to $2000 \mathrm{mg}$ of ICS (beclomethasone dipropionate), but with continuous symptoms and frequent exacerbations of BA. Group 3, patients with well-controlled, stable, and moderate persistent BA $(n=13$, median age 48 years, $\mathrm{FEV}_{1} \geq 70 \%$ ) regularly treated with a daily dose of 800 to $1000 \mathrm{mg}$ of ICS.

BALF was also obtained from 14 (median age 23.5 years) healthy subjects (Table 1). None had a history of any respiratory or systemic diseases or any current medical symptoms. None had had acute respiratory tract infection during the 6 weeks before the study. Lung function was normal and bronchodilator test was negative in all control subjects. All controls were nonsmokers. None was allergic, as judged by history and by negative results of skin prick tests with a panel of commonly used allergens (ALK-Abello). Of the study group, bronchial biopsy specimens (Table 2) were obtained from five steroid-naive BA patients, four uncontrolled severe persistent BA patients, five controlled moderate persistent BA patients, and six healthy subjects. The study protocol was approved by the Ethics Committee of Tartu University, Estonia, and informed consent was obtained from all patients before their enrollment to the study.

\section{Bronchoalveolar Lavage (BAL)}

BAL for the healthy controls was performed into the middle lobe. The BAL for BA patients was carried out from the lingula or middle lobe during bronchoscopy by use of a fiberoptic bronchoscope as previously described (Prikk et al, 2001; Sepper et al, 1994). Five $20-\mathrm{ml}$ aliquots of prewarmed $\left(37^{\circ} \mathrm{C}\right) 0.9 \% \mathrm{NaCl}$ were instilled into the segmental bronchus. The solution with lavage material was immediately aspirated back after each aliquot. The first aliquot was excluded as a sample of bronchial lining fluid.

\section{Processing of BALF for Western Immunoblotting and BALF Cells for Immunocytochemistry and In Situ Hybridization}

After bronchoalveolar lavage, BALF was kept at $4^{\circ} \mathrm{C}$ and processed within 2 hours. BALF was centrifuged at $500 \times g$ for 15 minutes to separate the supernatant from the cell pellet. The supernatant was divided into $500 \mu \mathrm{l}$ aliquots and stored at $-70^{\circ} \mathrm{C}$ before analyzing. The cell pellet was suspended in $10 \mathrm{ml}$ PBS and gently mixed. The cell viability was assessed by Trypan blue exclusion. The cells were repelleted by centrifugation at $500 \times g$ for 15 minutes and the supernatant was separated. The cell pellet was resuspended in $1 \mathrm{ml}$ PBS and gently mixed. Cytocentrifuge slides of 40,000 cells/slide were prepared by Cytospin 3 (Shandon Scientific, Cheshire, United Kingdom) at $250 \times g$ for 10 minutes. The slides were air-dried for 1 hour and frozen at $-70^{\circ} \mathrm{C}$ for immunocytochemistry. For in situ hybridization, all of the solutions were treated with $0.1 \%$ diethylpyrocarbonate (DEPC). After preparation of cytospins, the slides were fixed in $4 \%$ paraformaldehyde at $4^{\circ} \mathrm{C}$ and then dehydrated in alcohol series $(50 \%, 70 \%$, and $100 \%)$ each for 10 minutes at room temperature. The slides were air-dried for 1 hour and then frozen at $-70^{\circ} \mathrm{C}$ for in situ hybridization. For differential cell counts, the slides were stained with Giemsa staining.

\section{Bronchial Tissue Biopsies}

Bronchial tissue biopsies were taken during bronchoscopic examination from 14 BA patients and 6 healthy controls. Bronchial tissue biopsies were taken from

Table 1. Clinical Characteristics of Study Group ${ }^{a}$

\begin{tabular}{lcccc}
\hline & $\begin{array}{c}\text { Steroid-naive BA } \\
(n=14)\end{array}$ & $\begin{array}{c}\text { Uncontrolled severe BA } \\
(n=13)\end{array}$ & $\begin{array}{c}\text { Controlled stable BA } \\
(n=13)\end{array}$ & $\begin{array}{c}\text { Healthy control } \\
(n=14)\end{array}$ \\
\hline Age (years) & $32.5(20-61)$ & $48(27-60)$ & $48(27-64)$ & $23.5(20-53)$ \\
Sex (M/F) & $6 / 8$ & $6 / 7$ & $5 / 8$ & $5 / 9$ \\
FEV $\%$ predicted & $89.5(76.5-111)$ & $37.5(29.2-59)$ & $82.3(70-106)$ & $105(84-125)$ \\
FVC (L) & $5.4(2.84-5.68)$ & $2.3(1.65-5.62)$ & $3.32(2.56-6.04)$ & $3.85(3.24-6.33)$ \\
Duration of asthma (years) & $4(1-10)$ & $14(5-30)$ & $10(2-20)$ & 0 \\
Allergy (yes/no) & $7 / 7$ & $8 / 5$ & $5 / 8$ & $0 / 14$ \\
\hline
\end{tabular}

BA, bronchial asthma.

${ }^{a}$ Data shown as median, with range in parentheses. 
Table 2. Content of Total Protein, ECP, and Cellular Profile in BALF Samples ${ }^{a}$

\begin{tabular}{lcccc}
\hline & Steroid-naive BA & Uncontrolled severe BA & Controlled stable BA & Healthy control \\
\hline Total protein & 36.5 & 36.3 & 36.3 & 34.1 \\
& $(27.29-27.29)$ & $(34.4-37.0)$ & $(35.8-36.7)$ & $(23.1-23.1)$ \\
ECP & 1.64 & 1.41 & 1.39 & 0.77 \\
& $(0-15.9)$ & $(0-38.46)$ & $(0-20.78)$ & $(0.36-0.36)$ \\
Total cell count & $0.54 \times 10^{6 \star}$ & $0.28 \times 10^{6}$ & $0.37 \times 10^{6}$ & $0.26 \times 10^{6}$ \\
& $\left(0.49-2.26 \times 10^{6}\right)$ & $\left(0.23-0.36 \times 10^{6}\right)$ & $\left(0.17-0.73 \times 10^{6}\right)$ & $\left(0.13-0.61 \times 10^{6}\right)$ \\
Differential cell counts (\%) & & & & \\
$\quad$ Macrophages & $61(54-89)$ & $57(49-82)$ & $49(44-73)$ & $59(48-77)$ \\
Epithelial cells & $25(29-34)$ & $19(3-35)$ & $33(25-48)$ & $27(5-49)$ \\
Lymphocytes & $8(6-11)$ & $3(3-4)$ & $6(1-17)$ & $9(1-12)$ \\
Eosinophils & $2(0-3)$ & $6(5-6)$ & $2(0-3)$ & $0.5(0-9)$ \\
Neutrophils & $0(0-3)$ & $5(2-16)$ & $1(0-7)$ & $4(0-9)$ \\
\hline
\end{tabular}

BA, bronchial asthma.

${ }^{a}$ Data shown as median with range in parentheses.

* Significantly different from controls.

the right upper and middle lobe bronchi with care to avoid regions close to carina. Two tissue biopsy specimens were snap-frozen in liquid nitrogen and stored at $-70^{\circ} \mathrm{C}$ until sectioned, and two tissue biopsies were fixed in $4 \%$ paraformaldehyde and embedded in paraffin, according to methods used for immunohistochemistry and in situ hybridization, respectively.
Measurements of Total Protein Content and ECP in BALF

Total protein in BALF was measured as previously described (Bradford, 1976). Briefly, the photoabsorbances of the sample were measured at $600 \mathrm{~nm}$ by using the protein-Bradford dye binding principle. A concentration curve was obtained from serial dilution of bovine serum albumin. ECP was assayed by using

Table 3. Degree of Epithelial Shedding

\begin{tabular}{|c|c|c|c|c|}
\hline \multirow[b]{2}{*}{ Patient group } & \multirow[b]{2}{*}{ Grade of epithelial shedding ${ }^{a}$} & \multicolumn{3}{|c|}{ MMP-8 ${ }^{b}$} \\
\hline & & Epithelial cells & Submucosal inflammatory cells & $\begin{array}{l}\text { Glandular } \\
\text { cells }\end{array}$ \\
\hline \multicolumn{5}{|l|}{ Steroid-naive BA } \\
\hline 1 & 3 & ++ & ++ & NP \\
\hline 2 & 2 & ++ & +++ & NP \\
\hline 3 & 2 & + & ++ & NP \\
\hline 4 & 2 & + & + & NP \\
\hline 5 & 2 & ++ & +++ & NP \\
\hline \multicolumn{5}{|c|}{ Uncontrolled severe BA } \\
\hline 1 & $3-4$ & ++ & +++ & NP \\
\hline 2 & 3 & ++ & ++ & NP \\
\hline 3 & $3-4$ & ++ & +++ & NP \\
\hline 4 & $3-4$ & +++ & ++ & NP \\
\hline \multicolumn{5}{|l|}{ Controlled stable BA } \\
\hline 1 & 2 & ++ & +++ & NP \\
\hline 2 & $2-3$ & ++ & ++ & NP \\
\hline 3 & $0-1$ & 0 & ++ & NP \\
\hline 4 & $3-4$ & ++ & +++ & NP \\
\hline 5 & $0-2$ & $0-++$ & +++ & +++ \\
\hline \multicolumn{5}{|l|}{ Healthy controls } \\
\hline 1 & 0 & 0 & + & NP \\
\hline 2 & 0 & 0 & 0 & NP \\
\hline 3 & 0 & 0 & $0-+$ & NP \\
\hline 4 & 0 & 0 & + & NP \\
\hline 5 & 0 & 0 & 0 & NP \\
\hline 6 & 0 & 0 & $0-+$ & NP \\
\hline
\end{tabular}

Results of semiquantitative analysis of MMP-8 protein expression.

${ }^{a}$ Grade of epithelial shedding: 0 , an intact epithelium; 1 , mild; 2, moderate; 3, extensive; 4, naked basement membrane.

${ }^{b}$ Semiquantitative analysis of MMP-8 expression: 0 , none; + , mild; ++ , moderate; +++ , abundant.

${ }^{c} \mathrm{NP}$, not present. 
specific radioimmunoassay (Kabi Pharmacia, Uppsala, Sweden) according to the manufacturer's recommendations.

\section{Immunohistochemical and Immunocytochemical Staining}

The immunohistochemical and immunocytochemical analyses were principally carried out as previously described (Mäkelä et al, 1999; Prikk et al, 2001). The polyclonal rabbit anti-human MMP-8 does not detect pure human MMP-1, -2, -3, -9, or -13. For immunostaining, the Vectastain Rabbit ABC Elite Kit (Vector Laboratories, Burlingame, California) was used according to the manufacture's instructions. Bronchial biopsies were embedded in OCT-medium and 5- $\mu \mathrm{m}$ serial sections were cut. The frozen bronchial tissue specimens and cytocentrifuged BALF cell slides were melted, air-dried, and fixed in acetone for 10 minutes at $4^{\circ} \mathrm{C}$. The endogenous peroxidase activity was blocked by incubation for 30 minutes with $0.6 \% \mathrm{H}_{2} \mathrm{O}_{2}$ in methanol. The nonspecific binding sites were blocked by incubation with normal goat serum (1:50) for 3 hours. Thereafter, the sections were incubated with polyclonal anti-MMP-8 (Hanemaaijer et al, 1997; Sorsa et al, 1999; diluted 1:1000) overnight at $4^{\circ} \mathrm{C}$ and then sections were incubated with biotinylated antirabbit immunoglobulin G (1:250) for 1 hour and with avidin-biotin complex $(1: 125)$ for 30 minutes. The sections were stained with 3-amino-9-ethylcarbazole (AEC) and counterstained with Mayer's hematoxylin. For negative control, the primary antibody was replaced with a correspondent nonimmune serum.

The immunoreactivities were semiquantified into four grades: 0 , none; + , mild; ++ , moderate; and +++ , abundant. The degree of bronchial epithelial shedding was semiquantified into four grades: 0 , an intact epithelium; 1 , mild shedding; 2 , moderate shedding; 3, extensive shedding; and 4, naked BM (Prikk et al, 2001).

\section{RNA Probes}

A 95-bp Sphl fragment of human MMP-8 cDNA (Hasty et al, 1990) was ligated into the pGEM-3Z(+)-vector. The probe has been tested by Northern hybridization for specificity and by sequencing. The vector was linearized with a suitable enzyme and a riboprobe transcription kit (Boehringer-Mannheim Biochemica, Mannheim, Germany) was used for transcription according to the manufacturer's instruction. The transcripts were labeled with digoxigenin-11-UTP for in situ hybridization, and a corresponding sense probe was used as control for nonspecific hybridization.

\section{In Situ Hybridization}

In situ hybridization with RNA probes was carried out as previously described (Mäkelä et al, 1999; Prikk et al, 2001). Before deparaffinization with xylene and rehydration, tissue sections were incubated at $65^{\circ} \mathrm{C}$ for 30 minutes. The cell slides were melted at room temperature and proceeded to prehybridization. The tissue sections were treated with proteinase $\mathrm{K}$ and fixed in
4\% paraformaldehyde in PBS. The sections were immersed in glycine (100 mM in PBS) and acetylated in $0.25 \%$ acetic anhydride in $0.1 \mathrm{M}$ triethanolamine after equilibration in 4x SSC before 2 hours prehybridization at $57^{\circ} \mathrm{C}$. The hybridization buffer contained $10 \mathrm{~mm}$ DTT, $250 \mu \mathrm{g} / \mathrm{ml}$ yeast t-RNA, $250 \mu \mathrm{g} / \mathrm{ml}$ salmon sperm DNA, 50\% deionized formamide, 4x SSC, 10\% (w/v) dextran sulfate, $0.02 \%(w / v)$ Ficoll, $0.02 \%$ (w/v) BSA, $0.02 \%(\mathrm{w} / \mathrm{v})$ polyvinylpyrrolidone. The prehybridization buffer was removed and hybridization buffer containing $400 \mathrm{ng} / \mathrm{ml}$ DIG-labeled antisense or sense probe was applied to each section and hybridized overnight at $57^{\circ} \mathrm{C}$. The posthybridization washes were made as follows: $2 \times 15$ minutes in $2 \times$ SSC, and $4 \times 15$ minutes in $0.1 \times \mathrm{SSC}$ at $65^{\circ} \mathrm{C}$. The sections were equilibrated for 10 minutes in buffer 1 (100 mM Tris- $\mathrm{HCl}, 150 \mathrm{~mm}$ $\mathrm{NaCl}, \mathrm{pH}$ 7.5). The sections were blocked with buffer 1 containing $0.1 \%$ Triton $\mathrm{X}-100$ and $2 \%$ normal goat serum for 30 minutes. The blocking solution was removed and buffer 1 containing $0.1 \%$ Triton $\mathrm{X}-100$, $1 \%$ normal goat serum, and alkaline phosphataseconjugated anti-digoxigenin Fab-fragments, diluted $1: 200$, was applied to the sections and incubated for 1.5 hours. The sections were washed in buffer 1 and equilibrated in detection buffer (100 mm Tris- $\mathrm{HCl}, 100$ $\mathrm{mm} \mathrm{NaCl}, 50 \mathrm{~mm} \mathrm{MgCl} 2, \mathrm{pH}$ 9.5). The alkaline phosphatase-conjugated anti-digoxigenin was detected with Fast Red (Boehringer Mannheim) solution. The staining was stopped with TE-buffer and counterstained with Mayer's hematoxylin.

\section{Western Immunoblot Analysis}

The molecular forms of MMP-8 were analyzed by Western immunoblot using specific rabbit polyclonal anti-human MMP-8 antibody (IgG fraction) as previously described (Hanemaaijer et al, 1997; Prikk et al, 2001; Sorsa et al, 1999). SDS-PAGE-gels for MMP-8 Western blots were not carried out under reducing conditions. After electrophoresis, the proteins in the gel were electrotransferred onto a nitrocellulose membrane (Bio-Rad Laboratories, Richmond, California). After the unoccupied sites were blocked with $3 \%$ gelatin, the membrane first reacted with the primary antibody (1:500) and then with alkaline phosphatase conjugated secondary antibody. Immunoreactive proteins were visualized by nitro blue tetrazolium (Sigma, St. Louis, Missouri) and 5-bromo-4-chloro-3indolyl-phosphate (Sigma). Quantitation was carried out by the Bio-Rad Model GS-700 Imaging Densitometer using the Analyst program (Sorsa et al, 1999).

\section{Statistical Analysis}

The results were analyzed by nonparametric KruskalWallis one-way ANOVA of ranks analysis and the Dunn test for multiple comparisons was used to study the differences between control and patient groups. Correlations were analyzed with the Spearman rank correlation test. Statistical significance was defined as a $p$ value of $<0.05$. The results are expressed as median and range. 


\section{References}

American Thoracic Society (1987). Standards for the diagnosis and care of patients with chronic obstructive pulmonary disease (COPD) and asthma. Am Rev Respir Dis 36:225-244.

Bachmeier BE, Nerlich AG, Boukamp P, Lichtinghagen R, Tschesche H, Fritz H, and Fink E (2000). Human keratinocyte cell lines differ in the expression of the collagenolytic matrix metalloprotienases $-1,-8$, and -13 and of TIMP-1. Biol Chem 381:509-516.

Balbin M, Fueyo A, Knäuper V, Pendas AM, Lopez JM, Jimenez MG, Murphy G, and Lopez-Otin C (1998). Collagenase 2 (MMP-8) expression in murine tissue-remodeling. J Biol Chem 273:23959-23968.

Barnes PJ (1993). Anti-inflammatory therapy for asthma. Annu Rev Med 44:229-242.

Birkedal-Hansen HW, Moore GL, Boden MK, Windsor LJ, Birkedal-Hansen B, DeCarlo A, and Engler JA (1993). Martix metalloproteinases: A review. Clin Rev Oral Biol Med 4:197250.

Bousquet J, Jeffery PK, Busse WW, Johnon M, and Vignola AM (2000). Asthma. From bronchoconstriction to airway inflammation and remodeling. Am J Respir Crit Care Med 161:1720-1745.

Bousquet J, Lacoste P, Chanez P, Vic P, Godard P, and Michel FB (1996). Bronchial elastic fibers in normal subjects and asthmatics. Am J Respir Crit Care Med 153:1648-1654.

Bradford MM (1976). A rapid and sensitive method for quantitation of microgram quantities of protein utilizing the principle of protein-dye binding. Anal Biochem 72:248-254.

Chubinskaja S, Huch K, Mikecz K, Cs-Szabo G, Hasty KA, Keuttner KE, and Cole AA (1996). Chondrocyte matrix metalloprotenase-8. Upregulation of neutrophil collagenase by interleukin-1- beta in human cartilage from knee and ankle joints. Lab Invest 74:232-240.

Cole AA, Chubinskaja S, Schumacher B, Huch K, Cs-Szabo G, Yao J, Mikecz K, Hasty KA, and Kuettner KE (1996). Chondrocyte matrix metalloproteinase-8. J Biol Chem 271: 11023-11026.

Cole AA and Kuettner KE (1995). MMP-8 (neutrophil collagenase) mRNA and aggrecanase cleavage products are present in normal and osteoarthritichuman articular cartilage. Acta Orthop Scand 26:98-102.

Corbel M, Lagente V, Theret N, Germain N, Clement B, and Boichot E (1999). Comparative effects of betamethasone, cyclosporin and nedocromil sodium in acute pulmonary inflammation and metalloproteinase activities in bronchoalveolar lavage fluid from mice exposed to lipopolysaccharide. Pulm Pharmacol Ther 12:165-171.

Crystal RG and Weibel ER (1991). Structural organization of the pulmonary interstitium. In: Crystal RG and West JB, editors. The lung scientific foundation. New York: Raven Press, 369-380.

Dahlen B, Shute J, and Howarth P (1999). Immunohistochemical localisation of the matrix metalloproteinases MMP-3 and MMP-9 within airways in asthma. Thorax 54: 590-596.

Djucanovic R, Wilson JW, Britten KM, Wilson SJ, Walls AF, Roche WR, Howarth PH, and Holgate ST (1992). Effect of inhaled corticosteroids on airway inflammation and symptoms of asthma. Am Rev Respir Dis 145:669-674.
Dunsmore SE, Saarialho-Kere UK, Roby JD, Wilson CL, Matrisian LM, Welgus HG, and Parks WC (1998). Matrilysin expression and function in airway epithelium. J Clin Invest 102:1321-1331.

Goldie J, Jordana M, Cox G, Ohtoshi T, Dolovich J, and Denburg J (1992). Fibroblast and other structural cells in airway inflammation. Am Rev Respir Dis 145:S14-S17.

Guidelines for diagnosis and management of asthma (1997). National Institutes of Health, National Heart and Blood Institute, Bethesda MD Publication. No 97-4015.

Hanemaaijer R, Sorsa T, Konttinen YT, Ding Y, Sutinen M, Vissre $\mathrm{H}$, van Hinsbergh VWM, Helaakoski T, Kainulainen T, Rönka H, Tschesche $H$, and Salo T (1997). Matrix metalloproteinase-8 is expressed in rheumatoid synovial fibroblast and endothelial cells. J Biol Chem 272:3150431509.

Hasty KA, Jeffrey JJ, Hibbs MS, and Welgus HG (1987). The collagen substrate specificity of human neutrophil collagenase. J Biol Chem 262:10048-10052.

Hasty KA, Pourmotabbed TF, Goldberg GI, Thompson JP, Spinella DG, Stevens RM, and Mainardi CL (1990). Human neutrophil collagenase. A distinct gene product with homology to other matrix metalloproteinases. J Biol Chem 265: 11421-11424.

Hoshino M, Takahashi M, Takai Y, and Sim J (1999). Inhaled corticosteroids decrease subepithelial collagen deposition by modulation of the balance between matrix metalloproteinase- 9 and tissue inhibition of metalloproteinase-1 expression in asthma. J Allergy Clin Immunol 104:356-363.

Jeffery PK, Godfrey RW, Adelroth E, Nelson F, Rogers A, and Johansson SA (1992). Effects of treatment of airway inflammation and thickening of basement membrane reticular collagen in asthma. Am J Respir Crit Care Med 155:1864-1871.

Kumagai K, Ohno I, Okada S, Ohkawara Y, Suzuki K, Shinya T, Nagase H, Iwata K, and Shirato K (1999). Inhibition of matrix metalloproteinases prevents allergen-induced airway inflammation in murine model of asthma. J Immunol 162: 4212-4219.

Laitinen LA, Heino M, Laitinen A, Kava T, and Haahtela T (1985). Damage of the airway epithelium and bronchial reactivity in patients with asthma. Am Rev Respir Dis 131:599606.

Mäkelä $M$, Larjava $H$, Pirilä $E$, Maisi $P$, Salo $T$, Sorsa $T$, and Uitto VJ (1999). Matrix metalloproteinase-2 (gelatinase-A) is related to migration of keratinocytes. Exp Cell Res 251:6778.

Mautino G, Capony F, Bousquet J, and Vignola AM (1999). Balance in asthma between matrix metalloproteinases and their inhibitors. J Allergy Clin Immunol 104:530-533.

Mautino G, Oliver N, Chanez P, Bousquet J, and Capony F (1997). Increased release of matrix metalloproteinase-9 in bronchoalveolar lavage fluid and by alveolar macrophages of asthmatics. Am J Respir Cell Mol Biol 17:583-591.

Michaelis J, Vissers MCM, and Winternbourn CC (1990). Human neutrophil collagenase cleaves alpha-1-antitrypsin. Biochem J 270:809-814.

Ohno I, Ohtani H, Nitta Y, Suzuki J, Hoshi H, Homma M, Isoyama S, Tanno $\mathrm{Y}$, Tamura G, Yamauchi K, Nagura H, and Shirato K (1997). Eosinophils as a source of matrix 
metalloproteinase-9 in asthmatic airway. Am J Respir Cell Mol Biol 16:212-219.

Palosaari H, Wahlgen J, Larmas M, Rönkä H, Sorsa T, Salo T, and Tjäderhane $L$ (2000). The expression of MMP-8 in odontoblast and dental pulp cells is down-regulated by TGF- $\beta 1$. J Dent Res 79:77-84.

Peat JK, Woolcock AJ, and Cullen K (1987). Rate of decline of lung function in subjects with asthma. Eur $\mathrm{J}$ Respir Dis 70:171-179.

Pirilä E, Ramamurthy N, Maisi P, McClain S, Kucine A, Wahlgren J, Golub LM, Salo T, and Sorsa T (2001). Wound healing in ovarectomized rats. Effects of chemically modified tetracycline (CMT-8) and estrogen on matrix metalloproteinases $-8,-13$ and type I collagen expression. Curr Med Chem 8:281-294.

Polito AJ and Proud D (1998). Epithelial cells as regulator of airway inflammation. J Allergy Clin Immun 102:714-718.

Prikk K, Maisi P, Pirilä E, Sepper R, Salo T, Wahlgren J, and Sorsa T (2001). In vivo collagenase-2 (MMP-8) expression by human bronchial epithelial cells and monocytes/macrophages in bronchiectasis. J Pathol 194:232-238.

Redington AE and Howarth PH (1997). Airway remodeling in asthma. Thorax 52:310-312.

Roche WR, Beasley R, Williams JH, and Holgate ST (1989). Subepithelial fibrosis in the bronchi of asthmatics. Lancet 11:520-524.

Sepper R, Konttinen YT, Ding Y, Takagi M, and Sorsa T (1995). Human neutrophil collagenase (MMP-8), identified in bronchiectasis BAL fluid, correlates with severity of disease. Chest 107:1641-1647.

Sepper R, Konttinen YT, Sorsa T, and Koski H (1994). Gelatinolytic and type IV collagenolytic activity in bronchiectasis. Chest 106:1129-1133.

Shapiro SD (1998). Matrix metalloproteinase degradation of extracellular matrix: Biological consequences. Curr Opin Cell Biol 10:602-608.

Shapiro SD, Campell EJ, Kobayashi DK, and Welgus HG (1991). Dexamethasone selectively modulates basal and lipopolysaccharide-induced metalloproteinase and tissue inhibitor of metalloproteinase production by human alveolar macrophages. J Immunol 146:2724-2729.
Shmid TM, Mayne R, Jeffrey JJ, and Linsenmayer TF (1986). Type $X$ collagen contains two cleavage sites for a vertebrate collagenase. J Biol Chem 261:4184-4189.

Sorsa T, Mäntylä P, Ronkä H, Kallio P, Kallis GB, Lundqvist C, Kinane DF, Salo T, Golub LM, Teronen O, and Tikanoja S (1999). Scientific basis of matrix metalloproteinase-8 specific chair-side test for monitoring periodontal and peri-implant health and disease. Ann NY Acad Sci 878:130-140.

Sottrup-Jensen L (1989). Alpha-1-macroglobulins: Structure, shape, and mechanism of proteinase complex formation. J Biol Chem 264:11539-11542.

Tervahartiala T, Pirilä E, Ceponis A, Maisi P, Salo T, Tuter G, Kallio P, Törnwall J, Srinivas R, Konttinen YT, and Sorsa T (2000). The in vivo expression of the collagenolytic matrix metalloproteinases (MMP-2, -8, -13, and -14) and matrilysin (MMP-7) in adult and localized juvenile periodontitis. J Dent Res 79:1969-1977.

Vignola AM, Riccobono L, Mirabella A, Profita M, Chanez P, Bellia V, Mauntino G, D'Accardi P, Bousquet J, and Bonsignore $G$ (1998). Sputum metalloproteinase-9/tissue inhibitor of metalloproteinse-1 ratio correlates with airflow obstruction in asthma and chronic bronchitis. Am J Respir Crit Care Med 158:1945-1950.

Wahlgren J, Maisi P, Sorsa T, Sutinen M, Tervahartilala T, Pirilä E, Teronen O, Hietanen J, Tjäderhane L, and Salo T (2001). Expression and induction of collagenases (MMP-8 and -13 ) in plasma cells associated with bone destructive lesions. J Pathol 194:217-224.

Warner JA, Julius P, Luttman W, and Kroegel C (1997). Matrix metalloproteinases in bronchoalveolar lavage fluid following antigen challenge. Int Arch Allergy Immunol 113:318-320.

Weiss SJ (1989). Tissue destruction by neutrophils. N Engl J Med 320:365-376.

Yao PM, Buhler JM, d'Ortho MP, Lebargy F, Delclaux C, Harf A, and Lafuma C (1996). Expression of matrix metalloproteinase gelatinases $A$ and $B$ by cultured epithelial cells from human bronchial explants. J Biol Chem 271: 15580-15589. 